\title{
Coupled fluctuations in element release during dolomite dissolution
}

\author{
Christine V. Putnis ${ }^{1} *$, Encarnación Ruiz-Agudo ${ }^{2}$ and Jörn Hövelmann ${ }^{1}$ \\ 1 Institut für Mineralogie, Universität Münster, Corrensstrasse 24, 48149, Münster, Germany \\ 2 Dept. Mineralogy and Petrology, University of Granada, Fuentenueva s/n, 18071 Granada, Spain
}

[Received 4 May 2014; Accepted 20 August 2014; Associate Editor: T. Stawski]

\section{ABSTRACT}

Atomic force microscopy has been used to determine more precisely the mechanism of the initial stages of dolomite dissolution. Analysis of outflow solutions initially shows fluctuations of both $\mathrm{Ca}$ and $\mathrm{Mg}$ release with concentrations of $\mathrm{Ca} \gg \mathrm{Mg}$. The dolomite surface dissolves congruently in the presence of slightly acidified water as confirmed by the regular spreading of characteristic rhombohedral etch pits. Direct in situ observations show that a new phase precipitates on the dissolving surface simultaneously. As the $\mathrm{Ca}$ and $\mathrm{Mg}$ release decreases with time, the precipitated phase can be seen to spread across the dolomite surface. These observations indicate that the apparent incongruent dissolution of dolomite is a two-step process involving stoichiometric dissolution with the release of $\mathrm{Ca}, \mathrm{Mg}$ and $\mathrm{CO}_{3}$ ions to solution at the mineral-fluid interface coupled with precipitation of a new Mg-carbonate phase. The coupled element release confirms the interface-coupled dissolutionprecipitation mechanism.

KEYWORDs: dolomite, dissolution, interface-coupled dissolution-precipitation, incongruent dissolution.

\section{Introduction}

Dolomite $\left(\mathrm{Ca}, \mathrm{Mg}\left(\mathrm{CO}_{3}\right)_{2}\right)$ is present in significant amounts in the Earth's crust and its dissolution together with that of other dominant carbonates, mostly calcite, partly control the $\mathrm{Ca}^{2+}$ and $\mathrm{CO}_{3}^{2-}$ budget of superficial waters as well as the global carbon cycle (Mackenzie and Andersson, 2013). When calcite dissolves, $\mathrm{Ca}^{2+}$ and $\mathrm{CO}_{3}^{2-}$ ions are released in equal quantities to solution. When dolomite dissolves, however, the measured elements released to solution are not in stoichiometric proportions to the solid phase. $\mathrm{Ca}^{2+}$ is well known to be released preferentially initially, especially at low $\mathrm{pH}$ where the dissolution rate is enhanced. Dolomite dissolution has been the subject of research (e.g. Busenberg and Plummer, 1982; Gautelier et al., 1999; Pokrovsky and Schott, 2001; Pokrovsky et al., 2005 and

* E-mail: putnisc@nwz.uni-muenster.de

DOI: 10.1180/minmag.2014.078.6.01 references therein), mostly aimed at determining surface speciation under varying conditions of $\mathrm{pH}, p \mathrm{CO}_{2}$ and salinity after a steady state of element release was reached. As stated by Pokrovsky and Schott (2001), reaching this steady state or equal release of $\mathrm{Mg}$ and $\mathrm{Ca}$ typically took between $8 \mathrm{~h}$ and 5 days. These previous studies were not focused on the early stages of dolomite dissolution. Busenberg and Plummer (1982) stated that dolomite dissolution is controlled by heterogeneous chemical reactions and that backward reactions stop dolomite dissolution almost completely, far from equilibrium. In general dolomite-dissolution studies have been restricted because of its low reaction rates compared to calcite and the poorly

This paper is published as part of a special issue in Mineralogical Magazine, Vol. 78(6), 2014 entitled 'Mineral-fluid interactions: scaling, surface reactivity and natural systems'. 
constrained relationship between cation ordering and reactivity in dolomite (e.g. Morse and Arvidson, 2002; Lüttge et al., 2003).

Various mechanisms have been proposed to explain the initial non-stoichiometric $\mathrm{Mg}^{2+}$ and $\mathrm{Ca}^{2+}$ release, among them that the strong hydration shell around $\mathrm{Mg}^{2+}$ ions hinders their release from the dolomite surface or that the forward dissolution proceeds by a number of steps whereby the $\mathrm{CaCO}_{3}$ component dissolves faster than the $\mathrm{MgCO}_{3}$ component, the latter being the rate-limiting step for dolomite dissolution (Busenberg and Plummer, 1982). The advancement of analytical techniques in the past two decades, however, has enabled a much more precise analysis and observation of reactions such as those occurring at a nano-scale at the mineral-fluid interface. When reactions can be observed directly in situ, the actual mechanisms occurring can be seen and recorded. Atomic Force Microscopy (AFM) is one such technique (RuizAgudo and Putnis, 2012). Because atomic force interactions are tracked, the resolution of topography in the $z$ direction is always at an atomic scale. Atomic force microscopy was employed by Urosevic et al. (2012), using in situ observations, to show that dolomite actually dissolves stoichiometrically but is coupled to the precipitation of a $\mathrm{Mg}$-carbonate phase at the mineral-fluid interface. The hypothesis is that on dissolution of the surface layers of the dolomite crystal, all crystal-building units are released equally into the interfacial fluid at the mineral-fluid boundary, which becomes supersaturated with respect to a new Mg-carbonate phase that then precipitates. The evolution of the solution composition can be analysed simultaneously, e.g. by inductively coupled plasma-optical emission spectroscopy (ICP-OES).

Urosevic et al. (2012) did not analyse flowthrough solution compositions systematically and presented only bulk analyses. The present study elucidates the actual dissolution mechanism of dolomite in terms of the element release in a time sequence from the first contact of slightly acidified water on the dolomite surface. Direct observations using AFM together with sequential element analyses provide a clear picture of element release during the dissolution of dolomite.

\section{Experimental procedure}

Chemically pure, optical-grade dolomite crystals from Eugui, Navarra, Spain, were cleaved immediately prior to experiments, to produce $\{10 \overline{1} 4\}$ surfaces on crystal fragments $\sim 4 \mathrm{~mm} \times$
$3 \mathrm{~mm} \times 1 \mathrm{~mm}$ in size. The surface area was measured by the BET method and found to be $0.02 \mathrm{~m}^{2} \mathrm{~g}^{-1}$. The high purity of the sample was confirmed by XRD (X-ray powder diffraction using a Philips X'PERT-PRO diffractometer) and ICP-OES (Varian Vista pro-axial). Solutions were made using double-deionized water (resistivity $>18 \mathrm{M} \Omega \mathrm{cm}$ ) and the solution $\mathrm{pH}$ was adjusted to 3 using $\mathrm{HCl}$. All solutions were prepared directly prior to each experiment to avoid re-equilibration with the atmosphere. The solutions contained no other ions apart from minor amounts of $\mathrm{H}$ and $\mathrm{Cl}$ and were therefore highly undersaturated with respect to any possible precipitating phase and far from equilibrium with respect to dolomite. The AFM experiments were carried out using a Digital Instruments Nanoscope III Multimode AFM (Bruker) fitted with a fluid cell (volume $50 \mu \mathrm{l}$ ) so that solutions of known composition could be passed over the dolomite surfaces within the O-ring sealed cell allowing no contact with air. The AFM was used in contact mode under ambient conditions of $T\left(22^{\circ} \mathrm{C}\right)$ and $P$. Observations were made on scanned areas of $2.5 \mu \mathrm{m} \times 2.5 \mu \mathrm{m}$ or $5 \mu \mathrm{m} \times 5 \mu \mathrm{m}$.

Pure water was first passed over the dolomite surface to both clean the surface and to adjust the AFM parameters. Following a couple of scans in water (neutral $\mathrm{pH})$, acidfied water $(50 \mu \mathrm{l}$ of $1 \mathrm{M}$ $\mathrm{HCl}$ in $100 \mathrm{ml} \mathrm{H}_{2} \mathrm{O}, \mathrm{pH} \mathrm{3}$, to increase the dissolution rate) was flowed continuously over the surface, at a rate of $2 \mathrm{ml} \mathrm{min}^{-1}$ giving an effective flow rate that ensures surface reaction control rather than diffusion-controlled reactions (Liang et al., 1996: Shiraki et al., 2000). Further details of the use of AFM for in situ mineral-fluid reactions are given by Ruiz-Agudo and Putnis (2012). The outflowing solutions were collected continuously at regular intervals $(2 \mathrm{~min}$ ) into $5 \mathrm{ml}$ units ready for $\mathrm{Ca}$ and $\mathrm{Mg}$ analysis with ICP-OES. Collections continued for up to $2 \mathrm{~h}$. The solutions were tested for $\mathrm{pH}$ and then analysed for $\mathrm{Ca}$ and $\mathrm{Mg}$ by ICPOES. Although the low concentration of $\mathrm{Ca}$ and $\mathrm{Mg}$ in the solutions (ppb - few ppm) limits the accuracy of the analyses (Arvidson at al., 2006), relative values under the same conditions are expected to be reliable. The experiments were repeated for reproducibility. Surface precipitates on the dolomite surfaces were analysed ex situ with Raman spectroscopy (Horiba Yvon XploRA) and EDX (energy dispersive X-ray analysis Oxford Instruments INCA system on a JEOL SEM JSM-6610-LV at $20 \mathrm{kV}$ ) after $\mathrm{C}$ coating in the latter case. 
Ex situ experiments were also performed in order to observe the dolomite surfaces and identify the precipitate formed on dissolution of the surface. Similar $4 \mathrm{~mm} \times 3 \mathrm{~mm} \times 1 \mathrm{~mm}$ dolomite rhombs were cleaved from the same dolomite crystal and then placed in beakers containing $4 \mathrm{ml}$ of the solution of acidified water used for the AFM experiments for 4 and 14 days. The crystals were then removed from the solution, dried immediately and prepared for analysis by XRD, EDX and Raman spectroscopy together with the crystals from the AFM experiments. A second set of experiments under the same experimental conditions was performed using powdered dolomite (average grain size $50-100 \mu \mathrm{m})$ to give extra possibilities for chemical analysis.
PHREEQC (Parkhurst and Appelo, 1999) modelling was performed to obtain possible solution speciation under the experimental conditions and to estimate the volume of interfacial fluid at the dolomite surface that would allow supersaturation with respect to a new phase as well as to identify the possible phase.

\section{Results}

Upon injection of deionized water into the fluid cell, the dolomite $\{10 \overline{1} 4\}$ surfaces were observed dissolving by the formation of rhombohedral etch pits (Fig. $1 a-b$ ). This etch pit form is characteristic of other carbonates, notably calcite, and is controlled by the underlying trigonal crystal structure. Unlike calcite which has, on average,
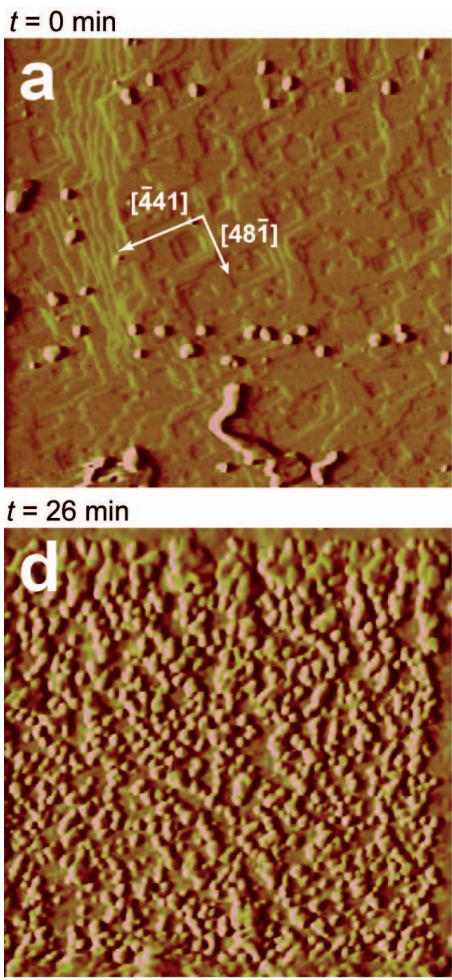

$t=16 \min$

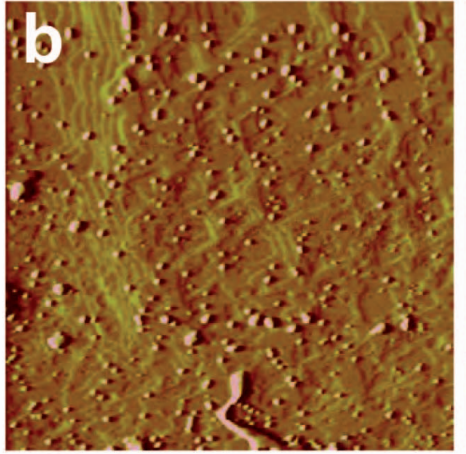

$t=32 \mathrm{~min}$

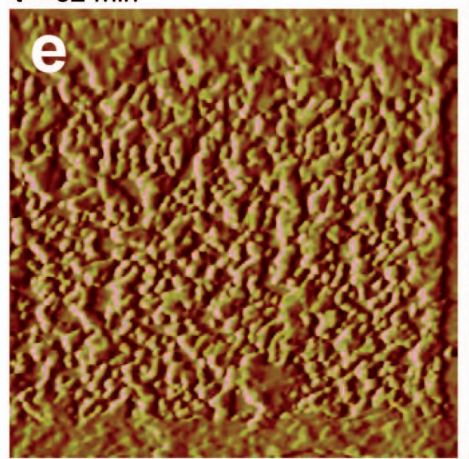

\section{$t=21 \mathrm{~min}$}

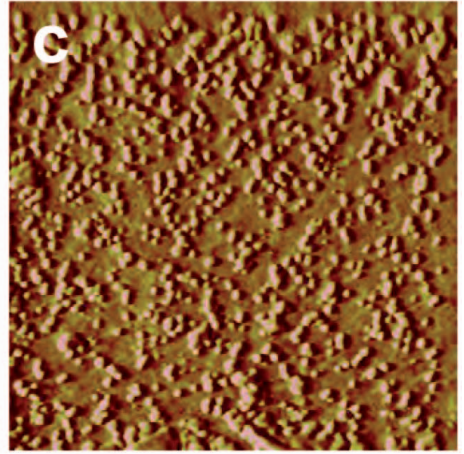

$t=39 \mathrm{~min}$

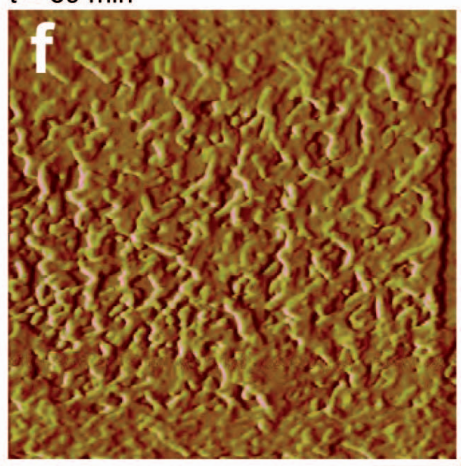

$500 \mathrm{~nm}$

FIG. 1. AFM contact-mode deflection images of a $\{10 \overline{1} 4\}$ dolomite cleavage surface reacting in the presence of flowing water at $\mathrm{pH}$ 3. (a) The flat surface after first contact with acidified water when a precipitate immediately starts to form; $(a-b)$ development of characteristic rhombohedral etch pits formed on the surface. The etch pits (crystallographic directions are marked on part $a$ ) nucleate and then spread progressively until a whole unit-cell layer $(\sim 3.0 \AA)$ of dolomite is removed. Simultaneously, precipitates are seen $(\mathrm{a}-e)$ nucleating and growing on the surface until the whole surface is almost covered $(f)$ with a Mg-carbonate layer. The times are indicated on the images and can be related to the plot of $\mathrm{Ca}$ and $\mathrm{Mg}$ release in Fig. 2. Image reproduced from Urosevic et al. (2012) with permission from Elsevier, license number: 3451340385562 . 
a nucleation of $1-10$ etch pits per $5 \mu \mathrm{m} \times 5 \mu \mathrm{m}$ area, each dolomite surface had a large nucleation of etch pits (an increase of at least an order of magnitude) that then enlarged slowly by etch-pitedge retreat or spreading. In most cases the pits were one unit cell deep $(\sim 3 \AA)$ and spread laterally until adjacent pits merged and eventually a whole unit-cell layer of dolomite was removed. The dissolution rate $\left(\sim 0.07-0.09 \mathrm{nms}^{-1}\right)$ was measured from the increase in etch-pit edges in consecutive images (as outlined by Urosevic et al., 2012) and the results were in the same range as measured by Urosevic et al. (2012).

Immediately after injection of acidified water $(\mathrm{pH} 3)$, small $(\max 100 \mathrm{~nm})$ rounded precipitates were seen forming on the dissolving surface as shown in Fig. 1. Initially these rounded particles could be swept aside by the scanning tip. With time more precipitates accumulated on the surface until the dolomite surface was covered with a layer of the new phase (Fig. 1f). None of the ex situ methods used for chemical analysis of the precipitate was successful. In all cases, for both crystal fragments and powder, only dolomite was detected by XRD, EDX and Raman spectroscopy.
The $\mathrm{Ca}$ and $\mathrm{Mg}$ concentrations measured using ICP-OES in the solutions collected during the dissolution of the dolomite surfaces are given in Fig. 2. The initial concentration of $\mathrm{Ca}(\sim 30 \mu \mathrm{M})$ was $\sim 60$ times greater than that of $\mathrm{Mg}(\sim 0.5 \mu \mathrm{M})$. The Ca release decreased exponentially during the experimental period $(1.5 \mathrm{~h})$, while the $\mathrm{Mg}$ concentration averaged $\sim 0.5 \mu \mathrm{M}$, similar to the initial concentration measured. Interestingly, both the $\mathrm{Ca}$ and $\mathrm{Mg}$ release showed coupled fluctuating oscillations. For $\mathrm{Ca}$ and $\mathrm{Mg}$ the fluctuation frequency was approximately one fluctuation $/ 4$ min, corresponding to the measurement period and this is equivalent to $1-2 \mu \mathrm{m} / \mathrm{min}$ and $0.1-0.05 \mu \mathrm{M} / \mathrm{min}$ for $\mathrm{Ca}$ and $\mathrm{Mg}$, respectively. The amplitude of the oscillations of $\mathrm{Ca}$ release declined until a steady value of $<1 \mu \mathrm{m}$ was reached after $\sim 1 \mathrm{~h}$. Magnesium showed a steadier release pattern, however, oscillating with a frequency coupled to that of $\mathrm{Ca}$ but the amplitude oscillated around the value of the initial release of $\sim 0.5 \mu \mathrm{M}$.

All solution $\mathrm{pH}$ values measured before and after the experiments remained at $\mathrm{pH} 3$.

The PHREEQC calculations showed that the bulk solution was undersaturated with respect to all phases. PHREEQC has also been used to estimate

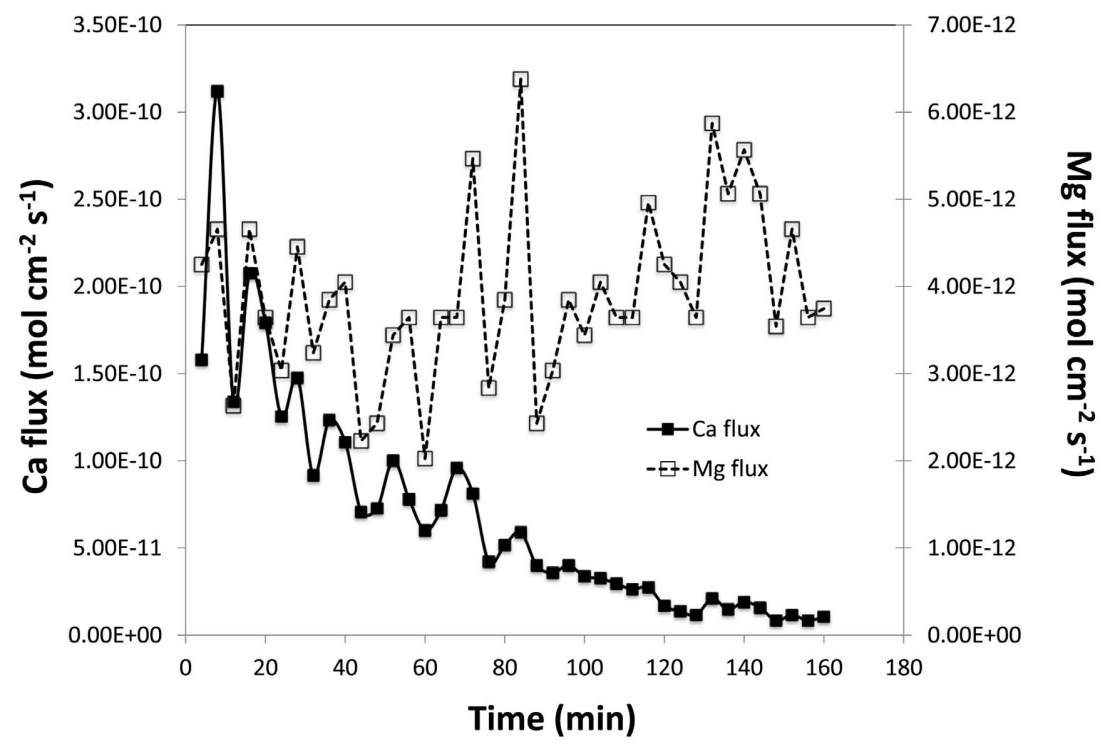

FIG. 2. A plot of the Ca (left ordinate and solid line) and $\mathrm{Mg}$ (right ordinate and dotted line) flux $\left(\mathrm{mol} \mathrm{cm}^{-2} \mathrm{~s}^{-1}\right)$ in the outflow solution after reaction of the dolomite surface with acidified water $(\mathrm{pH} 3)$. Note the different flux scales for $\mathrm{Ca}$ and $\mathrm{Mg}$. The release rates are plotted against time ( $\mathrm{min}$ ) and can be related to the images shown in Fig. 1. Both $\mathrm{Ca}$ and $\mathrm{Mg}$ release show oscillating fluctuations with time reflecting the coupled dissolution and precipitation processes occurring at the dolomite-water interface. Error bars are not indicated because instrument error $(1-2 \%)$ lies within the data point squares and sampling error is similar for all points plotted. 
the thickness of the boundary layer to reach supersaturation with respect to a highly soluble phase, nesquehonite (Urosevic et al., 2012 suggested that this is the phase forming at the surface). Assuming a $10 \mu \mathrm{m}$ thick layer (volume of fluid $2.1 \times 10^{-9} 1$ ), the calculations indicate that $2.9 \times 10^{-9}$ moles of dolomite should dissolve for this layer to become saturated with respect to nesquehonite. This amount of dolomite, in $2 \mathrm{ml}$ of solution (volume passed over the surface after each scan), represents a calcium concentration of 1.45 $\mu \mathrm{M}$ which is much lower than that measured in our experiments. Accordingly the solution at the interface would be highly supersaturated with respect to nesquehonite if the boundary layer was indeed $10 \mu \mathrm{m}$ thick. Additionally, this calculation shows that for a boundary layer thickness $<240 \mu \mathrm{m}$, the solution at the interface would be supersaturated with respect to nesquehonite.

\section{Discussion}

The non-stoichiometric release of $\mathrm{Ca}$ and $\mathrm{Mg}$ during the initial stages of dolomite dissolution has been reported previously (e.g. Pokrovsky and Schott, 2001). Urosevic et al. (2012) also confirmed a ratio of element release $\mathrm{Ca} / \mathrm{Mg}>1$ and suggested that this non-stoichiometric dissolution (sometimes referred to as incongruent dissolution, where the $\mathrm{Ca}$ and $\mathrm{Mg}$ release differs from the stoichiometry of the solid dolomite phase), can be explained by an interface-coupled dissolution-precipitation mechanism. Effectively this can be described as a two-phase process: (1) on contact of the acidified water with the dolomite surface, the surface begins to dissolve regularly, as seen in the nucleation and development of characteristic rhombohedral etch pits. This releases $\mathrm{Ca}, \mathrm{Mg}$ and $\mathrm{CO}_{3}$ ions to the solution at the mineral-water interface: (2) The release of these ions into the fluid boundary layer supersaturates this layer with respect to another phase, an $\mathrm{Mg}$-carbonate that then precipitates. The two processes are coupled at the interface and continue while element release remains possible. The solution flow over the surface ensures that diffusion of the released species into the solution within the fluid cell of the AFM is reduced, maintaining continuous, far-from-equilibrium conditions.

Etch pits formed on the dolomite surface contain equal numbers of $\mathrm{Ca}$ and $\mathrm{Mg}$ ions along

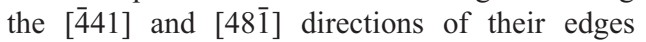
(Urosevic et al., 2012). It can be assumed, therefore, that during dissolution, equal amounts of $\mathrm{Ca}$ and $\mathrm{Mg}$ are released to solution as seen in the regular spreading of the etch pits. The precipitation of a Mg-carbonate phase, however, removes $\mathrm{Mg}$ from the solution and the $\mathrm{Ca}$ remains in the outflow solution, as seen in the initial high concentration of $\mathrm{Ca}$. If the element release shown in Fig. 2 is examined, a regular fluctuation in the release of both $\mathrm{Ca}$ and $\mathrm{Mg}$ is noted. Initially much more $\mathrm{Ca}$ is released to solution than $\mathrm{Mg}$ ( $\sim 60$ times more), then within the first few minutes the $\mathrm{Ca}$ release continues to increase as dissolution accelerates and then falls considerably (from $\sim 37 \mu \mathrm{M}$ to $15 \mu \mathrm{M}$ after a further $4 \mathrm{~min}$ ). The decline in $\mathrm{Ca}$ release continued exponentially during the measurement period and is consistent with the surface being covered progressively by the precipitating phase and effectively passivated from further dissolution. At the same time the $\mathrm{Mg}$ release is almost 2 orders of magnitude smaller than that of $\mathrm{Ca}$, indicating the immediate removal of the $\mathrm{Mg}$ released into the new phase on the surface. During the test period the Mg concentration released varied $(\sim 0.2 \mu \mathrm{M})$ around the same concentration as the initial measured value of $0.5 \mu \mathrm{M}$. Both $\mathrm{Ca}$ and $\mathrm{Mg}$ show regular (amplitude for $\mathrm{Ca} \sim 5 \mu \mathrm{M}$ and $\mathrm{Mg} \sim 0.5 \mu \mathrm{M}$ ) oscillatory element release on a short timescale of $\sim 4 \mathrm{~min}$, continuing for the measurement period of $1.5 \mathrm{~h}$. Each sample analysed contained solution collected during three consecutive scans indicating that the measured fluctuations were not linked to sampling error and the fluctuations in measured $\mathrm{Ca}$ and $\mathrm{Mg}$ did not simply coincide with sampling times. The element release represents coupled fluctuations reflecting the coupled processes of dissolution and precipitation.

Element release oscillations have not been reported during similar previous dolomite dissolution experiments, mainly because the oscillation period $(4 \mathrm{~min})$ is significantly shorter than the typical sampling times in other dissolution studies (e.g. Pokrovsky et al., 2005). Our observations confirm the work by Urosevic et al. (2012) and can be explained by the following:

(1) Water ( $\mathrm{pH} 3$ ) contacts the dolomite surface and initiates dissolution.

(2) $\mathrm{Ca}, \mathrm{Mg}$ and $\mathrm{CO}_{3}$ ions are released to the solution in equal amounts.

(3) Differential diffusion and/or retention rates of $\mathrm{Mg}$ and $\mathrm{Ca}$ results in the interfacial fluid becoming supersaturated with a Mg-carbonate phase that then precipitates, leaving mostly $\mathrm{Ca}$ to be released in the outflow solution. Steps $1-3$ occur very quickly as 
the dissolution and precipitation processes are coupled at the dissolving dolomite-solution interface. This is confirmed by the initial unequal release of elements where $\mathrm{Ca}$ is much greater $(\sim \times 60)$ than $\mathrm{Mg}$.

(4) Precipitation and continuous element diffusion towards the bulk solution removes $\mathrm{Mg}$ and $\mathrm{CO}_{3}$ from the interfacial solution that is then undersaturated with respect to dolomite and the precipitation phase and so dissolution of the surface (and also the new $\mathrm{Mg}$ phase) continues.

(5) The continued release of $\mathrm{Ca}, \mathrm{Mg}$ and $\mathrm{CO}_{3}$ again supersaturates the interfacial fluid and once again a Mg-carbonate phase precipitates.

(6) The process is repeated as long as a dolomite surface is present and in contact with the acidified water. This is seen in Fig. 2 in terms of the short-term coupled oscillating fluctuations of the release of both $\mathrm{Ca}$ and $\mathrm{Mg}$.

(7) As the dolomite surface becomes increasingly covered by the $\mathrm{Mg}$-carbonate phase (as seen in Fig. 1f) less $\mathrm{Ca}, \mathrm{Mg}\left(\mathrm{CO}_{3}\right)_{2}$ is available to dissolve as reflected in the overall continuous decrease in the Ca release shown in Fig. 2. The dolomite surface is effectively being passivated from further dissolution. As stated above, however, the new $\mathrm{Mg}$ phase may also dissolve to uncover more dolomite. Eventually a steady state of element release may be approached as seen by the final release measurement of $\sim 1 \mu \mathrm{M}$ and $0.5 \mu \mathrm{M}$ for $\mathrm{Ca}$ and $\mathrm{Mg}$, respectively.

For the reasons above, it can be understood that in the experiments by Pokrovsky and Schott (2001) it took up to 5 days to approach a steadystate element release from a dissolving dolomite surface. Kinetic and thermodynamic information obtained from studies based only on total concentrations of dissolved ions released may not be truly representative of the dissolution mechanism.

The lack of success in identifying the precipitate from both the AFM and ex situ experiments is probably due to the fact that the thickness and the total amount of the Mg phase was too small to be measurable by XRD and EDX analysis. A small thickness of the precipitated layer also makes identification by Raman spectroscopy problematic because the axial resolution of the Raman system is typically on the order of a few $\mu \mathrm{m}$. Hence, if the layer is considerably thinner than $1 \mu \mathrm{m}$, the Raman laser will mostly probe the underlying dolomite. This leaves us to hypothesize that, because the phase that precipitates is thin, it is therefore outside the detection limits of the analytical methods used. This is confirmed by the AFM measurements where this layer is only several unit cells deep - maximum $20 \mathrm{~nm}$.

As the initial solution was acidified water containing minor amounts of $\mathrm{HCl}$ and dolomite dissolution could be observed directly, the only elements going into solution were $\mathrm{Ca}, \mathrm{Mg}$ and $\mathrm{CO}_{3}$. $\mathrm{pH}$ measurements of solutions before and after experiments remained at $\mathrm{pH} 3$ as the solution flow $(2 \mathrm{ml} / \mathrm{min})$ was too large and the dissolution rate too low for any element release to show an influence on the bulk solution $\mathrm{pH}$. The element release showing $\mathrm{Ca}>>\mathrm{Mg}$, allows us to conclude that the new phase must be a $\mathrm{Mg}$ carbonate. In addition, as stated in the results section, PHREEQC (Parkhurst and Appelo, 1999) calculations show that for a boundary layer thickness $<240 \mu \mathrm{m}$, the solution at the interface would be supersaturated with respect to nesquehonite. Nevertheless, this calculation implies that nesquehonite forms directly from solution (without amorphous precursors or any other precursor phase), an assumption that cannot be proven at the moment.

Urosevic et al. (2012) had partial success in identifying the surface precipitate as a hydrated $\mathrm{Mg}$-carbonate phase (possibly nesquehonite, $\mathrm{MgCO}_{3} \cdot 3 \mathrm{H}_{2} \mathrm{O}$ ) by using grazing-incident angle $X$-ray diffraction (GIAXRD). During similar AFM dissolution experiments using carbonated water on brucite $\left(\mathrm{Mg}(\mathrm{OH})_{2}\right)$, Hövelmann et al. (2012) used XRD successfully to identify the surface precipitate as possibly dypingite, $\mathrm{Mg}_{5}\left(\mathrm{CO}_{3}\right)_{4}(\mathrm{OH})_{2} \cdot 5\left(\mathrm{H}_{2} \mathrm{O}\right)$. It is suggested here that the precipitate is also likely to be a hydrated Mg-carbonate.

By direct in situ observations of mineral-fluid reactions it is possible to decipher the mechanisms of processes occurring at the mineral surface. Our AFM observations show clearly that apparent incongruent dissolution of dolomite is a two-step process involving stoichiometric dissolution coupled with precipitation of a new phase at the dolomite mineral surface. AFM has also been used to show a similar element release mechanism occurring during the dissolution of wollastonite $\left(\mathrm{CaSiO}_{3}\right)$ (Ruiz-Agudo et al., 2012). From these results and also the work of Hellmann et al. (2012) the implication is that interface-coupled dissolution-precipitation may be a universal mechanism whenever minerals are in contact with aqueous solutions with which they are out of equilibrium (Putnis, 2009). 
This reinforces the importance of the mineralfluid interfacial layer in the control of these processes (Putnis and Ruiz-Agudo, 2013). The solution composition at the mineral surface must then be the rate-controlling factor in many mineral-fluid reactions. In the present experiments, the solutions used were undersaturated (far-from-equilibrium) with respect to any possible precipitating phase but precipitation was seen to occur. Therefore we can conclude that regardless of the bulk fluid composition, reactions at the mineral-fluid interface and the resultant element release into the interfacial fluid or boundary layer control possible replacement reactions. The composition of the bulk fluid has an influence, therefore, on which phase may supersaturate the interfacial fluid layer. The fluctuations in element release measured during the early stages of dolomite dissolution confirm the coupling of the processes of dissolution and precipitation at the fluid-mineral interface.

\section{Acknowledgements}

This research was carried out within the European FP7 Initial Training Networks MINSC and $\mathrm{CO}_{2-}$ REACT. ER-A also acknowledges the receipt of a Ramón y Cajal grant from the Spanish Government (Ministerio de Economia y Competitividad) as well as funding by the Spanish Government and European Commission (grant MAT2012-37584 - ERDF) and the Junta de Andalucía (research group RNM-179 and project P11-RNM-7550). The authors thank Veronika Rapelius for help with the ICP-OES analyses.

\section{References}

Arvidson, R.S., Collier, M., Davis, K.J., Vinson, M.D., Amonette, J.E. and Luttge, A. (2006) Magnesium inhibition of calcite dissolution kinetics. Geochimica et Cosmochimica Acta, 70, 583-594.

Busenberg, E. and Plummer, L.N. (1982) The kinetics of dissolution of dolomite in $\mathrm{CO}_{2}-\mathrm{H}_{2} \mathrm{O}$ systems at 1.5 to $65^{\circ} \mathrm{C}$ and 0 to 1 atm $\mathrm{PCO}_{2}$. American Journal of Science, 282, 45-78.

Gautelier, M., Oelkers, E.H. and Schott, J. (1999) An experimental study of dolomite dissolution rates as a function of $\mathrm{pH}$ from -0.5 to 5 and temperature from 25 to $80^{\circ} \mathrm{C}$. Chemical Geology, 157, 13-26.

Hellmann, R., Wirth, R., Daval, D., Barnes, J-P., Penisson, J-M., Tisserand, D., Epicier, T., Florin B. and Hervig, R.L. (2012) Unifying natural and laboratory chemical weathering with interfacial dissolution-reprecipitation: A study based on nanometer-scale chemistry of fluid-silicate interfaces. Chemical Geology, 294-295, 203-216.

Hövelmann, J., Putnis, C.V., Ruiz-Agudo, E. and Austrheim, H. (2012) Direct nanoscale observations of $\mathrm{CO}_{2}$ sequestration during brucite $\left[\mathrm{Mg}(\mathrm{OH})_{2}\right]$ dissolution. Environmental Science and Technology, 46, 5253-5260.

Liang, Y., Baer, D.R., McCoy, J.M., Amonette, J.E. and LaFemina, J.P. (1996) Dissolution kinetics at the calcite-water interface. Geochimica et Cosmochimica Acta, 60, 4883-4887.

Lüttge, A., Winkler, U. and Lasaga, A.C. (2003) Interferometric study of the dolomite dissolution: a new conceptual model for mineral dissolution. Geochimica et Cosmochimica Acta, 67, 1099-1116.

Mackenzie, F.T. and Andersson, A.J. (2013) The marine carbon system and ocean acidification during Phanerozoic time. Geochemical Perspectives, 2, $1-227$.

Morse, J.W. and Arvidson, R.S. (2002) The dissolution kinetics of major sedimentary carbonate minerals. Earth Science Reviews, 58, 51-84.

Parkhurst, D.L. and Appelo, C.A.J. (1999) Users guide to PHREEQC (version 2) - a computer program for speciation, batch reaction, one-dimensional transport, and inverse geochemical calculations. U.S. Geological Survey Water-Resources Investigation Report, 99-4259.

Pokrovsky, O.S. and Schott, J. (2001) Kinetics and mechanism of dolomite dissolution in neutral to alkaline solutions revisited. American Journal of Science, 301, 597-626

Pokrovsky, O.S., Golubev, S.V. and Schott, J. (2005) Dissolution kinetics of calcite, dolomite and magnesite at $25^{\circ} \mathrm{C}$ and 0 to 50 atm $\mathrm{pCO}_{2}$. Chemical Geology, 217, 239-255.

Putnis, A. (2009) Mineral replacement reactions. Pp. 87-124 in: Thermodynamics and Kinetics of WaterRock Interactions (E.H. Oelkers and J. Schott, editors). Reviews in Mineralogy and Geochemistry, 70, Mineralogical Society of America, and the Geochemical Society, Chantilly, Virginia, USA.

Putnis, C.V. and Ruiz-Agudo, E. (2013) The mineralwater interface: where minerals react with the environment. Elements, 9, 177-182.

Ruiz-Agudo, E. and Putnis, C.V. (2012) Direct observations of mineral-fluid reactions using atomic force microscopy: the specific example of calcite. Mineralogical Magazine, 76, 227-253.

Ruiz-Agudo, E., Putnis, C.V., Rodriguez-Navarro, C. and Putnis, A. (2012) Mechanism of leached layer formation during chemical weathering of silicate minerals. Geology, 40, 947-950.

Shiraki, R., Rock, P.A. and Casey, W.H. (2000) 
Dissolution kinetics of calcite in $0.1 \mathrm{M} \mathrm{NaCl}$ solution at room temperature: An atomic force microscopic (AFM) study. Aquatic Geochemistry, 6, 87-108.

Urosevic, M., Rodriguez-Navarro C., Putnis, C.V.,
Cardell, C., Putnis, A. and Ruiz-Agudo, E. (2012) In situ nanoscale observations of the dissolution of $\{10 \overline{1} 4\}$ dolomite cleavage surfaces. Geochimica et Cosmochimica Acta, 80, 1-13. 